\title{
CAUSALIDADE ENTRE EDUCAÇÃO E CRESCIMENTO ECONÔMICO: Uma revisão da literatura e a contribuição brasileira ao debate
}

\section{CAUSALITY BETWEEN EDUCATION AND ECONOMIC GROWTH: a literature review and the Brazilian contribution for the discussion}

\author{
Rodrigo Calmon Ribeiro ${ }^{1}$ \\ Solange C. Inforzato Souza²
}

\begin{abstract}
RESUMO
O objetivo deste trabalho é mostrar o debate sobre a causalidade entre a educação e o crescimento econômico, os principais métodos para a identificação da direção da causalidade e a contribuição brasileira para o tema. A resenha metodológica sobre a relação de causa entre a educação e o crescimento econômico revela que a sua estimação empírica se sobrepõe ao conceito de precedência temporal de variáveis. Nesse aspecto, a literatura nacional mostra que o nível do ensino fundamental mantém uma relação de causalidade em direção ao crescimento econômico; em comparação aos estudos internacionais, possui divergência quanto ao ensino superior, uma vez que as pesquisas internacionais verificaram que o crescimento econômico possui relação de precedência do ensino superior, fenômeno não encontrado nos trabalhos nacionais. Além disso, a disponibilidade de trabalhos brasileiros sobre o assunto é proporcionalmente menor do que os internacionais e replicam métodos utilizados em outros trabalhos.
\end{abstract}

Palavras-chave: Educação. Crescimento Econômico. Causalidade.

\section{Abstract:}

The aim of this work was to present a discussion about the link between education and economic growth, the main methods to identify the direction of causality and the Brazilian contribution to this topic. The methodology review regarding the causal relationship between education and economic growth shows that their empirical estimation overlaps the concept of temporal precedence. Based on this, the national literature shows that the elementary school level maintains a relationship of causality in direction to economic growth; when compared to international studies, there were divergence on higher education, since international research found that economic growth has precedence relationship of higher education, a phenomenon not found in the Brazilian works. In addition, the availability of Brazilian works on the subject is proportionately smaller than the international and replicate methods used in other articles.

Keywords: Education. Economic Growth. Causality.

JEL: I25, J24, C10

\footnotetext{
1 Economista pela Universidade Estadual de Londrina, Londrina, Paraná, Brasil. E-mail: rodrigocalmonribeiro@gmail.com

${ }^{2}$ Economista pela Universidade Estadual de Londrina, Londrina, Paraná, Brasil. Mestre em Ciências Econômicas e doutora em Educação pela Pontifícia Universidade Católica de São Paulo, São Paulo, São Paulo, Brasil. Atualmente, é professora senior da Universidade Estadual de Londrina.E-mail : solangecassia@uol.com.br
} 


\section{INTRODUÇÃO}

A relevância da educação e seu papel na sociedade como mantenedora da ordem social e como meio de assegurar a concorrência dos mercados e a prosperidade de uma nação, estão contemplados na literatura econômica desde Adam Smith. Nessa perspectiva teórica, Smith (1983) destaca a qualidade das instituições educadoras, sua função na geração do conhecimento e contribuição para a melhoria da produtividade dos trabalhadores, assim como para o crescimento econômico do país.

Em ampla gama de trabalhos que estudam os retornos da educação nos salários individuais, considera-se a educação como parte do capital humano e fator aditivo ao trabalhador que incrementa a sua produtividade e seus salários. É, todavia, amplamente reconhecido na literatura econômica que a educação, bem como a experiência no mercado de trabalho, a migração e a saúde são partes constitutivas do capital humano. No entanto, a influência do ambiente econômico também pode ter impacto tanto na decisão do indivíduo de investir na educação quanto na decisão de ingressar no mercado de trabalho, nas expectativas dos agentes, nos custos da escolarização, entre outras. Em trabalhos como os de Becker (1962), Ghez e Becker (1975), Schultz (1973) e Mincer (1974, 1981), esses argumentos começaram a ser empiricamente testados.

Por outro lado, a escolha da proxy para a medida da educação, ou do capital humano, na análise econômica mostra-se fundamental e, apesar dos questionamentos em relação à sua utilização, o seu emprego resulta em trabalhos de boa qualidade e são importantes para a ciência econômica, tanto no que se refere às relações entre a educação e os retornos individuais como para a natureza macroeconômica dessa relação e sua causalidade.

Além da relevância e das limitações encontradas em estimar os seus retornos individuais, é natural pensar que haja uma causalidade bem estabelecida entre a educação e o crescimento econômico de um país. Contudo, há controvérsias em relação aos resultados dos estudos macroeconômicos empíricos ${ }^{3}$ no sentido da causalidade: se a educação é o fator que causa o crescimento ou se o crescimento econômico é o impulsionador da educação.

Alguns trabalhos chegam à conclusão de que a educação é fator indutivo do crescimento econômico, como o de Meulemeester e Rochat (1995); por outro lado, Bils e Klenow (2000) coloca em xeque essa questão. Esses últimos pontuaram que os trabalhos anteriores a eles generalizam e consideram que todos os níveis educacionais são motivadores do crescimento econômico.

A partir dessa controvérsia, deu-se início a diversos estudos que variam em suas metodologias quanto à escolha das bases de dados e a seleção do nível educacional ideal para tal. Há estudos em que são expostas as duas linhas possíveis: a educação causa crescimento econômico e, ao mesmo tempo, o inverso é verdadeiro. É possível observar, deste modo, que quando diferem os métodos e técnicas utilizados, o sentido da causalidade pode mudar e suas interpretações, por conseguinte.

Diante disso, o objetivo deste artigo é mostrar o debate sobre a causalidade entre educação e crescimento econômico, os principais métodos para a identificação

${ }^{3}$ Para mais detalhes sobre a discussão, ver Venniker (2000). 
da direção da causalidade e a contribuição brasileira. Para isso, a próxima seção expõe os conceitos e as pesquisas sobre o capital humano e, particularmente sobre a educação. A terceira seção trata da discussão sobre causalidade e sobre as abordagens estatísticas e econométricas utilizadas na literatura, e a quarta documenta e discute as evidências empíricas internacionais e nacionais sobre a direção da causalidade entre educação e crescimento econômico.

\section{CONTRIBUIÇÃO DO CAPITAL HUMANO PARA OS INDIVÍDUOS E PARA A NAÇÃO: raízes conceituais e evidências}

\section{Retornos do Capital Humano e evidências}

Smith (1983) explicou que há cinco razões para os ganhos pecuniários em alguma atividade produtiva: a primeira, a característica do trabalho (se é agradável ao trabalhador ou não); a segunda, a facilidade e o custo do aprendizado para atuação no emprego; a terceira, a existência deste emprego no tempo; a quarta, a confiabilidade imputada nos empregados pelos patrões na colocação deste no posto de trabalho; e quinta, a probabilidade de sucesso do trabalhador neste posto (e a probabilidade de sucesso da função no ambiente fabril).

Muito embora o tema da aprendizagem estivesse presente em Smith (1983), a primeira tentativa de estimar o valor monetário do trabalhador foi de William Petty em 1691. O objetivo de Petty foi demonstrar o poder que a Inglaterra possuía no quesito 'trabalho', o valor monetário da vida humana que é destruído em guerras, e os efeitos econômicos da migração (Hull, 1899, apud Kiker 1966). O método utilizado foi o cálculo da perpetuidade em relação aos salários pagos, com base na taxa de juros de mercado.

A crítica a isso, no entanto, segundo Kiker (1966), é a de que, como o custo de manutenção do trabalhador não é considerado no cálculo, o método não é adequado uma vez que é necessário saber dos indivíduos o sexo, idade, classe social, entre outros fatores, para resultar em um valor mais preciso. O trabalho de Farr (1853) apresentou o primeiro método científico para este fim e foi amplamente utilizado por anos. Ele levou em consideração o fluxo descontado de rendimentos do homem na Inglaterra em sua época, subtraindo seus custos de manutenção. ${ }^{4}$ Porém, aplicada esta técnica de análise, os resultados eram questionáveis: quanto mais jovem uma pessoa era mais impostos ela pagava sobre uma renda que, provavelmente, não auferia.

Ernst Engel, por volta de 1883, estimou o valor monetário de um ser humano diferentemente de Petty. Segundo ele, o valor que um ser humano possui não é possível de determinar, mas é possível determinar os custos que os pais têm na criação de uma pessoa. Isso poderia ser estimado com a fórmula, utilizando a notação de Kiker (1966):

$$
C_{x}=c_{o}\left\{1+x+k\left[\frac{x(x+1)}{2}\right]\right\}
$$

\footnotetext{
${ }^{4}$ Esta metodologia tinha como objetivo um método de tributação ótima. Um indivíduo que possuiria um nível mais elevado de educação auferiria maior renda do que outro com menor nível escolar. Os custos de manutenção seriam as despesas pessoais do indivíduo. Esta hipótese é impraticável nos tempos atuais.
} 
em que $C_{x}$ é o custo total de produzir um ser humano (excluído os juros, depreciação e manutenção até a idade $x ; c_{o}$ é o custo do nascimento e $k$ é o percentual de aumento do custo por ano. Engel (1883) apud Kiker (1966) assumiu que o indivíduo estaria totalmente produzido quando atingido 26 anos. Embora esta forma de estimar o valor monetário de um ser humano pareça de pouco uso, modificando a equação é possível, segundo Kiker (1966), determinar os fatores determinantes do valor do capital humano, tal como educação e serviços de saúde.

List e Henderson (1983) destacaram a importância do capital humano para um país, sendo este o componente mais importante do capital de uma nação, além de sua importância para a produção e distribuição de renda. A importância se dava pela dependência da indústria com o setor de ciência e inovação.

Nos modelos de crescimento econômico, os modelos endógenos demonstraram que a taxa de crescimento da economia é exógena e igual a taxa de crescimento do progresso tecnológico. Lucas (1988), baseado no modelo de Uzawa (1965), pontua que esta não é uma observação consistente. ${ }^{5}$ Em seu modelo, Lucas (1988) mostra que políticas de incentivo à acumulação de capital humano têm impactos permanentes na taxa de crescimento da economia. ${ }^{6}$ Romer (1992) incorpora o setor de inovação em seu modelo, sendo um setor utilizador do fator de produção do capital humano. O impacto na taxa de crescimento dependia da quantidade de pesquisa e pesquisadores alocados em centros de pesquisa.

No tocante à adaptabilidade da tecnologia na produção, Nelson e Phelps (1966) afirmam que a economia aumenta seu nível de produtividade quanto maior a dotação de capital humano disponível e quanto maior for a distância em relação à fronteira tecnológica. Assim, a escolaridade tem impacto direto na incorporação de novas tecnologias pelas firmas, resultando em um aumento da taxa de crescimento da economia pelo aumento da produtividade total dos fatores.

Para Schultz $(1972,1973)$, ao elevar a produtividade, a educação é o fator mais importante de um país como determinante do crescimento e para a melhora na distribuição de renda dos indivíduos. Pelo fato de tanto o emprego quanto os salários da mão de obra qualificada serem relativamente insensíveis ao ciclo econômico, como pontua Mincer (1981), um país cresceria a uma taxa maior se houvesse mais mão de obra qualificada.

Diante do exposto, esta pesquisa revisa a bibliografia sobre os retornos individuais da educação e estende a análise para um contexto macroeconômico.

Em muitos trabalhos são realizados procedimentos utilizando o modelo minceriano (Mincer, 1974), cujos coeficientes referem-se à taxa de retorno da educação nos rendimentos do trabalhador. Os resultados empíricos obtidos em relação aos retornos da educação para os indivíduos convergem, em sua grande maioria, à estimação de Mincer, mesmo com os possíveis vieses da estimação do modelo por Mínimos Quadrados Ordinários (MQO).

Heckman e Li (2004) utilizaram variáveis instrumentais, MQO e correção de Heckman $^{7}$, e encontraram resultados convergentes aos retornos mincerianos para a

\footnotetext{
${ }^{5}$ Lucas (1988) aponta que a abordagem tradicional não explica o comportamento das economias do leste asiático.

${ }^{6}$ Isto é possível graças à hipótese de que os investimentos em capital humano eram abaixo do nível ótimo da economia.

${ }^{7}$ A correção de Heckman é um procedimento de dois estágios para correção do viés de seleção. $O$ primeiro estágio, baseado na teoria econômica, é composto pela estimação de um modelo probit. No segundo estágio, o pesquisador corrige pela seleção amostral incorporando uma transformação das probabilidades individuais como variável explanatória.
}

44 Economia \& Região, Londrina (Pr), v.8, n.2, p.41-67, jul./dez. 2020 
China em 2000. Cada ano adicional no ensino superior resultou em $11 \%$ de acréscimo no rendimento dos trabalhadores.

Confirmando a média de um ano adicional em escolaridade no aumento dos salários, Psacharopoulos e Patrinos (2004) demonstram, em uma estimação para 42 países, que os maiores retornos estão em países com renda baixa. Todas as estimações, corroborando as evidências de Mincer, na média, foram de 10\%. Nesta mesma linha, Trostel, Walker e Woolley (2002) sugeriram uma média de retorno da educação em países desenvolvidos por volta de $5 \%$ para homens e pouco mais de $6 \%$ para mulheres. Países menos desenvolvidos obtiveram uma variação de até $6 \%$ desta média, chegando a $12 \%$.

No Brasil, os retornos de cada ano escolar giram em torno dos resultados internacionais, tendo como trabalhos iniciais os de Langoni (1974) e Senna (1976), que estimaram os retornos adicionais da educação em 12,5\%; Sachsida, Loureiro e Mendonça (2004), em que as estimativas giravam em torno de $12 \%$ a $14 \%$ de retorno salarial; Barbosa Filho e Pessôa (2008), utilizando a taxa interna de retorno, calcularam os retornos da escolaridade em nível pré-escolar, médio e superior, em média $14 \%$.

Rodrigues (2010) captou um efeito adicional de 13,13\% para mulheres, em 2008 , e de $12,16 \%$ para homens utilizando a correção de Heckman, corroborando a afirmação de Psacharopoulos e Patrinos (2004) que as mulheres apresentam um maior retorno em escolaridade em relação aos homens. Kassouf (1994) sugeriu que, para homens, cada ano adicional na educação corresponde à $7,2 \%$ de ganhos na taxa de salário, comparado a $7,7 \%$ no método minceriano tradicional. ${ }^{8}$ Também, indivíduos $^{2}$ com maior grau de escolaridade, vivendo em regiões com maior desenvolvimento, tendem a ter salários maiores. Para mulheres, porém, a cada ano adicional na educação corresponde à $8,5 \%$ de ganhos na taxa de salário, comparado a 7,0\% do método tradicional.

Resende e Wyllie (2006), utilizando a PPV-IBGE ${ }^{9}$ e a correção de Heckman, estimou em $12,6 \%$ o retorno para os homens, $1,7 \%$ a menos se não considerar a correção do viés de seleção amostral. Para mulheres, foi de 15,9\%.

O background familiar é, também, fator fundamental para os rendimentos do trabalhador. Utilizando a metodologia de Brunello e Checchi (2005), Júnior e Sampaio (2015) demonstraram que a educação do pai influencia em 5,1\% na educação do filho, aumentando em $0,1 \%$ os rendimentos. Outro resultado importante é que os maiores retornos da educação são para quem possui uma qualidade escolar menor (menor razão professor-aluno) e que os pais possuam, no máximo, educação primária. Desta maneira, é possível observar que não apenas os fatores como anos de estudo e experiência tem importância fundamental nos retornos da educação, mas também outros determinantes como background familiar, qualidade da escola, qualidade da moradia e outros fatores econômicos externos às características do indivíduo.

Outra maneira de estimar os retornos à educação ocorre por meio da Taxa Interna de Retorno (TIR) tratada por Schultz (1961), Mincer (1958) e Becker (1962). Este método sugere que o agente maximiza o valor presente de sua renda, escolhendo a quantidade de anos de educação e descontado a uma taxa de desconto que se iguale aos custos da aquisição da educação (custo monetário e de oportunidade).

\footnotetext{
${ }^{8}$ Em seu artigo, a estimação da taxa de salário foi realizada pela Correção de Heckman.

${ }^{9}$ A Pesquisa de Padrões de Vida (PPV-IBGE) foi realizada nos anos de 1996 e 1997.
} 
No Brasil, os primeiros trabalhos utilizando esta metodologia foi o de Castro (1970) e Langoni (1974). Eles calcularam os retornos do investimento em educação para a década de 1960 no Brasil e seus resultados indicaram que era extremamente rentável a aplicação de recursos em educação.

Moura (2008) estimou os retornos da educação com a Taxa Interna de Retorno de Becker (1975), utilizando a Pesquisa Nacional por Amostra de Domicílios (PNAD) de 1999 a 2004 e relaxando hipóteses que levam à interpretação de que o coeficiente minceriano seja igual à taxa interna de retorno da educação nos rendimentos do trabalhador. O autor verificou que as estimativas são menores quando as hipóteses são relaxadas, mas ainda assim há uma convergência para os resultados internacionais.

Barbosa Filho e Pessôa (2008) estimaram as taxas de retorno para os níveis distintos de educação. Para a educação primária e ginasial, as taxas se mantiveram acima de $10 \%$ para o período analisado (1981 a 2004). Para o ensino médio, o retorno se manteve em média em $14 \%$, e para a pré-escola os retornos se situaram acima de $15 \% .{ }^{10}$

A tentativa de estimar os retornos de educação para diferentes idades, anos escolares e características do trabalhador funda-se nos preceitos da Teoria do Capital Humano. O desafio para os pesquisadores está na escolha da variável que melhor identifica o capital humano, comentada a seguir.

\section{A escolha da proxy como especificação do capital humano}

Um dos fatores principais para a escolha da metodologia para estimar o impacto da educação, seja no âmbito da renda pessoal como no crescimento econômico e sua causalidade, se dá pela escolha da proxy para a representação do Capital Humano. Algumas proxies serão tratadas a seguir e discutidas por Wöbmann (2000).

\section{Taxa de matrícula dos níveis educacionais e taxa de analfabetismo}

Barro e Sala-i-Martin (1995) contribuem para o debate com a inserção da taxa de matrícula como uma boa proxy para representar a educação como capital humano, fundamental em modelos econométricos para a estimação do efeito da educação no crescimento econômico.

Asteriou e Agiomirgianakis (2001) utilizam o número de matriculados no ensino primário, secundário e superior para determinar a taxa de variação do capital humano para a Grécia no período entre 1960 e 1994, e verificaram que uma variação nos níveis básico e fundamental de educação podem ter um impacto positivo no crescimento econômico. Higgins, Levy e Young (2004) propõem a porcentagem da população que tem mais de oito anos de escolaridade, anos de ensino superior incompletos e graduação completa como proxy ótima para este fim de estimação. Souza (1999) aponta que uma boa proxy pode ser a taxa de analfabetismo do país estudado.

Entretanto, Bils e Klenow (2000) criticam veemente esta abordagem por afirmarem que a taxa de matrícula, por ser uma variável de fluxo, não pode captar o comportamento do estoque de capital humano de uma nação. Sendo assim, os resultados do trabalho de Barro e Sala-i-Martin são frutos da omissão de uma variável

\footnotetext{
${ }^{10}$ Segundo o autor, estimar os retornos da educação para o nível pré-escolar é ineficaz com uma metodologia generalista. Deste modo, o autor estima em metodologia específica.
}

46 Economia \& Região, Londrina (Pr), v.8, n.2, p.41-67, jul./dez. 2020 
altamente correlacionada com taxa de matrícula e o crescimento econômico do período posterior.

Wöbmann (2000) expõe que a taxa de matrícula não representa a população que está alocada na produção, uma vez que o conhecimento adquirido pelas crianças matriculadas não consegue influenciar o produto do país por não se relacionar diretamente com o estoque de capital humano produtivo do momento, apesar de ser utilizada em algum momento futuro. Também, segundo Hanushek e Kimko (2001), a taxa de matrícula não é utilizada corretamente pelo fato de que parte de estudantes do ensino superior não está na PEA. Outro ponto que o evidencia é que parte da taxa de matrícula tem "efeito duplicado", isto é, alguns estudantes repetem o ano letivo ou abandonam os estudos. Em suma, a utilização da taxa de matrícula como proxy do capital humano pode não representar uma medida de mudanças do país.

\section{Taxa de alfabetização adulta do país}

A taxa de alfabetização é definida como a habilidade do indivíduo em ler e escrever uma simples sentença e é utilizada como proxy do estoque de capital humano de um país em regressões cross-country de crescimento. Estudos como Azariadis e Drazen (1990) e Romer (1990) utilizam essa proxy e defendem que a taxa de alfabetização adulta oferece resultados satisfatórios.

Normalmente utilizada pela facilidade de captação dos dados, Wöbmann (2000) pontua que a alfabetização adulta não reflete os investimentos realizados em capital humano, tanto em nível de país quanto em nível de indivíduos (qualquer investimento direcionado a áreas científicas, logísticas, analíticas, não são captadas por esta proxy).

\section{Anos completos de estudo e média de anos de escolaridade}

Grande parte dos trabalhos elaborados utilizam os anos completos de educação dos indivíduos, captando os anos de educação formal recebida pela força de trabalho. Entre eles estão Benhabib e Spiegel (1994), Lindahl e Krueger (2001), Temple (1999), Barro e Sala-i-Martin (1995). A forma de construção e organização da base de dados influencia na metodologia dos trabalhos.

\section{Qualidade do capital humano}

Outro fator a ser considerado para a inserção do capital humano é a sua qualidade. Segundo Nakabashi e Figueiredo (2005a) e Nakabashi e Figueiredo (2005b), a qualidade do capital é mais importante do que a sua quantidade. A qualidade do capital humano deve ser dividida entre a qualidade da variável de fluxo e de estoque. Assim, a qualidade do estoque de capital humano é diferente da qualidade da variável representativa de fluxo de educação como proxy.

A dificuldade na utilização de uma proxy para a qualidade do capital humano adquirido é a de que é improvável que as pesquisas captem a capacidade intelectual dos indivíduos de maneira similar e em lugares diferentes. A primeira série do ensino médio no Brasil, por exemplo, teria de ser igual ao mesmo nível escolar em outros países para fins de comparação.

Hanushek e Kimko (2000) utilizaram bases de dados internacionais de resultados de testes de matemática e ciências para 39 países, buscando analisar o 
impacto da educação sobre o crescimento, controlando pela educação. Este trabalho é baseado no de Bishop (1992) e partem da premissa de que o conhecimento em ciências e matemática seria uma forma de mostrar a importância da pesquisa e do desenvolvimento no país. O modelo utilizado pelos autores leva em consideração a qualidade da força de trabalho, recursos direcionados às escolas e à produção de capital humano e outros fatores que determinam estes recursos. Encontraram uma alta aplicabilidade dos resultados de testes internacionais de matemática e ciências como proxy do capital humano.

Em suma, é possível verificar que a escolha da proxy é fundamental para a medida da inserção do capital humano na análise econômica e, apesar de questionamentos contrários à utilização destas proxies, o seu emprego ainda resulta em trabalhos de boa qualidade e são importantes para a Economia.

Depois de discutidas as relações entre educação ou capital humano e retornos individuais da educação, este trabalho prossegue para a evolução dos trabalhos que discutem metodologias de causalidade e sua aplicabilidade.

\section{SOBRE A CAUSALIDADE E AS ABORDAGENS ESTATÍSTICAS E ECONOMÉTRICAS}

Hume (1742), um dos principais filósofos-economistas, mantinha um ceticismo quanto a uma ação ter, necessariamente, uma causa definida provinda de outra ação. Para Hume (1777) apud Hoover (2006), nem a experiência nem a lógica seriam capazes de gerar uma segurança para afirmar uma regra geral sobre a causa de um evento. "Causas podem ser necessariamente conectadas a efeitos; mas, para Hume, nós nunca iremos saber em que esta condição necessária consiste" (Hume, 1777 apud Hoover, 2006, p. 3, tradução nossa).

Mill (1851), ao contrário de Hume, apenas duvidava quanto à aplicabilidade da causalidade na Economia. Em sua obra, desenvolveu seus métodos de indução: o método de aceitação, diferença, dupla aceitação e diferença e o método de resíduos e variações concomitantes. Segundo o autor, se dois conjuntos de acontecimentos obtiverem um resultado diferente, ou seja, um fenômeno está presente em um conjunto, mas não em outro, e este fenômeno corresponder a um dos métodos de indução, então este método seria a causa deste fenômeno. Pelo fato do autor ter afirmado em Princípios de Economia Política, de 1848, que a economia era uma ciência separada das outras e era inexata, estes princípios eram conhecidos, essencialmente, a priori. ${ }^{11}$

No século XIX, contudo, a expansão e utilização da estatística na economia possibilitaram avanços no sentido de garantir a possibilidade de estimar a causa de um fenômeno. Jevons (1863) apud Hoover (2006) construiu índices para determinar a relação de causa entre inflação e o aumento do estoque de ouro após 1849, com base no preceito de resíduos de Mill (1851). Edgeworth (1885) desenvolveu testes de significância, enfatizando o significado de um resultado ser valido estatisticamente como se este vinha "como causa" de outro fenômeno.

Com o desenvolvimento da análise de regressão (simples e múltipla), percebeu-se que o método colocava uma direção causal definida: a direção da regressão deve

\footnotetext{
${ }^{11}$ Hoover (2006) aponta que estes princípios foram influenciadores de várias correntes diferentes de pensamento na economia, tendo como exemplo Mises e os Austríacos; segundo o autor, levaram estes preceitos como base da sua visão, afirmando que a economia não poderia ser uma ciência empírica.
} 
respeitar a direção da causalidade. Ou seja, a regressão de $Y$ por $X$ não produz coeficientes estimados que sejam algebricamente inversos aos coeficientes estimados de $\mathrm{X}$ por $\mathrm{Y}$.

Porém, segundo Hoover (2006), uma vez que a economia era regida pela determinação simultânea de variáveis, podia-se incorrer em erros sobre a direção da causalidade nas análises de regressões. Em uma economia com a visão dominante de Equilíbrio Parcial (estendendo-se ao Equilíbrio Geral de Walras), os preços e as quantidades são determinados simultaneamente.

Simultaneidade não requer uma relação causal definida, podendo ser espelhada apenas como uma correlação simétrica não causal. Deste modo, não seria possível distinguir sobre o lado do mercado que se estaria analisando: da curva de oferta ou da curva de demanda. Este é o conceito básico do problema de identificação. Normalmente visto como um sistema de equações, o problema de identificação consta da inserção de fatores que possam ser os determinantes das variáveis $\mathrm{Y}$ e $\mathrm{X}$ (variáveis exógenas).

A relação de causalidade na Econometria é estudada desde a formação da Comissão Cowles ${ }^{12}$, em 1932. Diferentes abordagens podem ser consideradas para o estudo de causalidade de variáveis, como a abordagem de análise do processo (abordagem inferencial estrutural), cujo principal autor foi Hermann Wold, que enfatizou a assimetria da causalidade. Ele é base dos modelos de causalidade de Granger e VARs.

A segunda abordagem era a da seleção das variáveis exógenas (ou instrumental) em assunções a priori baseadas na teoria econômica, como assinalava Mill (1851). Simon (1953), contudo, mostrou que a causalidade poderia ser definida não apenas entre variáveis exógenas e endógenas, mas também entre as variáveis endógenas entre si. Também demonstrou que uma relação de ordem causal bem definida é equivalente às condições bem definidas de identificação das variáveis.

A terceira abordagem relaciona a causalidade com as propriedades invariantes dos modelos econométricos estruturais. Ela enfatiza a distinção de variáveis endógenas, exógenas e identificação e estimação de parâmetros estruturais das regressões.

\section{Abordagem Inferencial Estrutural}

A abordagem inferencial estrutural considera o conceito de precedência temporal das variáveis. Considere o sistema

$$
\begin{gathered}
Y_{t}=\theta X_{t}+\epsilon_{1 t} \\
X_{t}=\epsilon_{2 t}
\end{gathered}
$$

em que os termos de erro são independentes (não correlacionados) e $\theta$ parâmetro. Simon (1953) afirma que $X_{t}$ causa $Y_{t}$ pelo fato de $X_{t}$ ser dependente (organizado a

\footnotetext{
12 A Comissão Cowles é um instituto para pesquisas em Economia, fundada em 1932 por Alfred Cowles, empresário e economista. A Comissão era dedicada a estabelecer o link entre teoria econômica e a matemática. Suas principais contribuições foram a criação e consolidação da Teoria do Equilíbrio Geral e da Econometria. Dentre seus pesquisadores, estavam Kenneth Arrow, Gérard Debreu, James Tobin, Franco Modigliani, entre outros.
} 
frente) de $Y_{t}$. Ou seja, deve-se saber o valor de $X_{t}$ para determinar o valor de $Y_{t}$. Deste modo, (2) controlaria (1).

Contudo, escrevendo as equações da forma (1) e (2) não garante que esta seja simétrica em informações ou que exerça controle uma sobre a outra. Exemplificando de outra forma, considere o sistema:

$$
\begin{gathered}
Y_{t}=\omega_{1 t} \\
X_{t}=\sigma Y_{t}+\omega_{2 t}
\end{gathered}
$$

em que $\sigma=\frac{\theta \operatorname{var}\left(\epsilon_{2}\right)}{\theta^{2} \operatorname{var}\left(\epsilon_{2}\right)+\operatorname{var}\left(\epsilon_{1}\right)}, \omega_{1}=\epsilon_{1}+\theta \epsilon_{2 t}$ e $\omega_{2}=(1-\sigma \theta) \epsilon_{2 t}-\sigma \epsilon_{1 t}$. Neste caso, na abordagem de Simon (1953), $Y_{t}$ causaria $X_{t}$, mesmo apresentando a mesma forma reduzida (1) e (2) mas com direção de causalidade diferente. Ambos os sistemas se encaixam perfeitamente nos dados, porém podem apresentar conclusões ambíguas quanto à causalidade. A causalidade corre da esquerda para a direita em um dos sistemas (4), enquanto que no outro corre da direita para a esquerda (1) e (2).

Para resolver este problema de equivalência observacional, Simon (1953) se basearia em experimentos que permitiria a escolha dos parâmetros estruturais. Com o experimento, ele poderia verificar qual dos sistemas apresentaria os parâmetros estruturais que refletiria a verdadeira estrutura de causalidade dos dados. Se um experimento alterasse a distribuição condicional de $X_{t}$ e não alterasse a distribuição marginal de $Y_{t}$, então quer dizer que $Y_{t}$ é fator causador de $X_{t}$. Uma mudança apenas afetaria os parâmetros $\sigma$ e $\epsilon_{2}$ (afetaria apenas a variância $\omega_{2 t}$ ), deixando assim $\omega_{1 t}$ intacto. Assim, apenas o sistema composto pelas equações (3) e (4) apresentaria melhor adequabilidade aos dados.

Deste modo, essa seria uma maneira de levantar evidências sobre a causalidade de uma variável para a outra por meio de inferência estatística, sem o uso de hipóteses a priori.

\section{Abordagem do Processo A Priori}

Baseada nas ideias do filósofo Herbert Feigl que explica a causação em termos da previsibilidade de acordo com um conjunto de leis, Zellner (1979) define lei como uma descrição probabilística de uma sucessão de estados de mundo que é válido para condições de fronteira e cobre várias circunstâncias possíveis.

A questão que possa surgir é saber como diferenciar as leis das falsas generalizações. Ou seja, como diferenciar as relações condicionais independentes de intervenções, de situações que não são tanto invariantes, sendo que estas podem ser completamente acidentais. Para Zellner (1979), uma teoria é capaz de distinguir entre leis e generalizações casuais pelo fato de que são suportadas por hipóteses e axiomas que são consistentes ao longo do tempo. Uma lei é aplicável em um quadro-situação finito, sendo possível extrapolar a análise para o infinito.

\section{Abordagem do Processo Inferencial}

A abordagem mais conhecida e utilizada de um processo inferencial relacionado à causalidade é o procedimento de Granger (1969). Este processo não é baseado na teoria econômica: é uma abordagem probabilística de causalidade, buscando evidenciar um fator que eleva a probabilidade de um efeito. Ou seja,

$$
A \text { causa } B \text { se } P(B \mid A)>P(B)
$$


A assimetria da causalidade entre A e B é assegurada por condicionar a ocorrência de $\mathrm{A}$ antes de ocorrer $\mathrm{B}$. Não há causalidade das variáveis eliminadas se a distribuição marginal e a distribuição condicional das variáveis restantes forem a mesma.

\section{Definição de não-causalidade de Granger}

$\mathrm{Na}$ definição demonstrada em Hendry (2017), seja $X_{o}$ as informações iniciais até o tempo $t=0$ do vetor de séries temporais $\left\{x_{t}\right\} \in \mathcal{R}$, e $X_{t-1}=\left(X_{0}, x_{1}, \ldots, x_{t-1}\right)=$ $\left(X_{0}, X_{t-1}^{1}\right)$. A função densidade de probabilidade conjunta de $x_{t}$ para $t=1, \ldots, T$ é escrita como $D_{x_{T}^{1}}$ e então $D_{x_{t}^{1}}\left(X_{t}^{1} \mid X_{0}\right)$. Fatorando sequencialmente, temos:

$$
D_{X_{t}^{1}}\left(X_{T}^{1} \mid X_{0}\right)=\prod_{t=1}^{T} D_{x_{t}}\left(x_{t} \mid X_{t-1}\right)
$$

que é a função densidade de probabilidade condicional de $X_{t}^{1}$. Após este passo, para verificar a relação necessária para testar-se a não causalidade, particiona-se $x_{t}=$ $\left(x_{1}, x_{2}\right)$ em $\left(x_{t, 1}, x_{t, 2}\right)$ e fatorando para cada $D_{x_{t}}\left(x_{t} \mid X_{t-1}\right)$ :

$$
D_{X_{T}^{1}}\left(X_{T}^{1} \mid X_{0}\right)=\prod_{t=1}^{T} D_{x_{1, t} \mid x_{2, t}}\left(x_{1, t} \mid x_{2, t}, X_{t-1}\right) D_{x_{2, t}}\left(x_{2, t} \mid X_{t-1}\right)
$$

Para satisfazer esta fatoração condicional-marginal, particiona-se $X_{t-1}$ em $X_{1, t-1}$ e em $X_{2, t-1}$. Então:

$$
D_{X_{t}^{1}}\left(X_{T}^{1} \mid X_{0}\right)=\prod_{t=1}^{T} D_{x_{1, t} \mid x_{2, t}}\left(x_{1, t} \mid x_{2, t}, X_{t-1}, X_{2-t}\right) D_{x_{2, t}}\left(x_{2, t} \mid X_{1, t-1}, X_{2, t-1}\right)
$$

Definição 1: Se $D_{x_{2, t}}($.$) não depender de X_{1, t-1}$, assim sendo:

$$
D_{x_{2, t}}\left(x_{2, t} \mid X_{1, t-1}, X_{2, t-1}\right)=D_{x_{2, t}}\left(x_{2, t} \mid X_{2, t-1}\right) \quad \forall t
$$

então $x_{1}$ não causa $x_{2}$ no sentido de Granger.

Com isso, a não causalidade de Granger implica, de acordo com a equação (6), que a marginalização da distribuição de $\left\{x_{2}\right\}$ com respeito às informações passadas de $\left\{x_{1}\right\}\left(X_{1, t-1}\right)$, não tem efeito na distribuição condicional. Ou seja,

$$
\prod_{t=1}^{T} D_{x_{2, t}}\left(x_{2, t} \mid X_{1, t-1}, X_{2, t-1}\right)=\prod_{t=1}^{T} D_{x_{2, t}}\left(x_{2, t} \mid X_{2, t-1}\right)
$$

O teste de não causalidade de Granger se baseia na irrelevância das informações passadas de $\left\{x_{1}\right\}$ como determinante para $\left\{x_{2}\right\}$. Se $X_{t-1}$ for o conjunto informacional do universo em $t=(1, \ldots, T)$, então a irrelevância de $X_{t-1}$ para $\left\{x_{2}\right\}$ não poderia justificar uma causa, de acordo com Hendry (2017).

Desta maneira, as informações presentes e passadas das duas variáveis a serem testadas são primordiais para saber a relação de causalidade e a possibilidade de determinação desta. A escolha da abrangência das informações é fundamental para 
a determinação da possibilidade de causalidade e, caso positiva, se é instantânea ou não.

Considere um exemplo com o sistema de regressões:

$Y_{t}=\phi_{11} Y_{t-1}+\phi_{12} X_{t-1}+\vartheta_{1 t}$,

$X_{t}=\phi_{21} Y_{t-1}+\phi_{22} X_{t-1}+\vartheta_{2 t}$

em que $\phi_{i j}$ são parâmetros e $\vartheta_{i j}$ são termos de erros aleatórios. O número de defasagens $(\mathrm{k})$ está contido no intervalo $(0, \infty)$, porém quanto mais próximo a 1 , melhor para uma explicação implícita geral. Deste sistema, $X_{t}$ causa $Y_{t+1}$ se $\phi_{12} \neq 0$ e $Y_{t}$ causa $X_{t+1}$ se $\phi_{21} \neq 0$.

A escolha do número de defasagens para que se possa fazer os testes de causalidade, segundo Davidson e MacKinnon (1993) é algo primordial para serem efetuados os testes. Segundo os autores, deve-se escolher o número de defasagens anteriormente à execução dos testes, pelo fato de que o analista possa decidir a exclusão de algumas defasagens para ajustar o modelo. A escolha de muitas defasagens pode implicar no viés de inclusão de variáveis irrelevantes, conceito básico da econometria. Contudo, poucas defasagens podem ocultar variáveis relevantes ao modelo.

Existe diferença entre o método de não-causalidade de Granger na teoria e na prática. Segundo Hendry (2017), o método de não-causalidade de Granger é não operacional, uma vez que o universo de informação é não observável. Granger (1969) baseou seu método em relação às mudanças na distribuição conjunta das variáveis observáveis: se deletar a história da variável do universo informacional não altera a distribuição conjunta de outra variável, então a variável omitida não causa (no sentido de Granger) a segunda. Desta maneira, o que é verificado em trabalhos acadêmicos é a tentativa do Teste Empírico de Não-Causalidade de Granger, que consiste em adicionar ou retirar defasagens de um conjunto de variáveis a fim de verificar sua significância. Desta maneira, de acordo com Henry (2017), os pesquisadores estariam confundindo correlação com causalidade.

Com isso, o conceito de Granger aplicado na maior parte dos trabalhos tem como objetivo determinar a precedência temporal de variáveis. Ou seja, os autores detalham que os resultados não implicam necessariamente em causalidade, mas que mudanças nas informações passadas de $X$ precedem as informações passadas da variável $Y$. Também pode ocorrer, nesse caso, a bicausalidade, em que se obtém relação de causalidade dos dois lados da equação.

Como base de comparação, Eichler (2012) demonstra quatro formas diferentes de causalidade, cada uma com suas definições e corolários que diferem entre si. $^{13} \mathrm{~A}$ atenção que o pesquisador deve ter em definir o método a ser utilizado, tendo conhecimento dos preceitos e implicações que a estatística apresenta nos resultados obtidos, deve ser máxima. A maior quantidade de informações sobre as variáveis escolhidas tem que ser levada em consideração.

A importância de se estudar a causalidade é fundamental para as formulações de política econômica e entendimento de como certas variáveis se comportam. $\mathrm{O}$ conhecimento sobre a direção de causalidade entre educação e crescimento econômico, para fim de política econômica, é motivo suficiente para haver investimentos no setor e possibilitar a construção de um padrão educacional mínimo em comparação com países mais desenvolvidos que o Brasil. Desta maneira, tornaria

\footnotetext{
${ }^{13} \mathrm{O}$ autor demonstra as seguintes causalidades em séries temporais: causalidade por intervenção, causalidade estrutural, causalidade de Granger e causalidade de Sims. Para detalhes, consultar Eichler (2012).
} 
o país referência no setor, atrairia investimentos em pesquisa e desenvolvimento, além dos benefícios sociais a longo prazo.

Contudo, esse é um debate que ainda não possui relação estabelecida sobre a direção da causalidade entre as variáveis. Pesquisadores encontram relações causais diferentes em relação ao sentido da causalidade, havendo conclusões de que o crescimento econômico causa a educação e, em outros, de que a educação causa o crescimento econômico. Alguns desses resultados estão documentados nas próximas seções, na ordem em que a direção da causalidade foi encontrada.

\section{EVIDÊNCIAS EMPÍRICAS SOBRE A DIREÇÃO DA CAUSALIDADE}

\section{Direção da causalidade: Educação - crescimento econômico}

Meulemeester e Rochat (1995) procuraram analisar a relação de causalidade entre a educação e o crescimento econômico para quatro países: Suécia, Reino Unido, Japão e França. A série utilizada continha dados entre 1885 e 1987. Eles encontraram indícios significativos sobre a causalidade unidirecional entre educação superior e crescimento econômico, partindo da primeira para a segunda.

Asteriou e Agiomirgianakis (2001) verificaram a mesma relação de causalidade para vários níveis educacionais na Grécia, em um cenário de reformas no ensino superior grego. Utilizaram o PIB per capita como proxy do crescimento econômico e sua taxa de crescimento. Para a educação, a taxa de matrícula dos estudantes do nível primário, secundário e superior foi utilizada. ${ }^{14}$ Utilizando a abordagem de Granger (1969), os autores constataram que todas as variáveis educacionais (exceto o ensino superior) causavam o crescimento econômico. O mesmo foi verificado para os gastos em educação, validando as políticas públicas direcionadas para gastos no âmbito educacional.

No entanto, os autores rejeitaram a hipótese alternativa na qual o ensino superior seja causador do crescimento econômico. Este resultado, além de ser um dos poucos que encontram relação significativa entre ensino superior e crescimento econômico, foi sugerido ${ }^{15}$ pela expansão das universidades que a Grécia proporcionou, levando a expansão de trabalhadores com diploma de universidades a ficarem desempregados quando o momento econômico se alterava. Ou seja, no período analisado (1960-1994), a economia seria favorável para os trabalhadores com baixo grau de qualificação.

Kui (2006) analisou a causalidade das variáveis para a China, no período entre 1978 e 1996, utilizando a abordagem de Granger (1969). Apesar de não ter encontrado relações de longo prazo entre as variáveis (cointegração), o autor verificou que existe uma relação de causa na direção da educação básica para o crescimento econômico com $5 \%$ de grau de significância e do ensino médio com $10 \%$ de significância. Também, verificaram relações significativas entre o ensino superior e o crescimento econômico, justificada pelos dados utilizados ou pela situação macroeconômica da China na época.

\footnotetext{
${ }^{14}$ Como proxy alternativa, os autores utilizaram os gastos públicos em educação em relação aos gastos totais do governo, como em Barro (1991).

${ }^{15}$ Há ênfase para estudos mais aprofundados sobre esta relação de causalidade. A maior parte dos trabalhos não encontra ou tem dificuldades em encontrar uma relação fixa para este nível de ensino.
} 
Yurtkuran e Terzi (2015) encontraram para o período entre 1950 e 2012 a relação entre estudantes completando a graduação, estudantes completando o ensino médio e os estudantes de ensino médio técnico, com o crescimento econômico para a Turquia. Para isso, utilizaram três metodologias: a causalidade padrão de Granger, a versão de Hsiao (1981) da causalidade de Granger e a de Dolado-Lutkepohl (1996), que analisam a causalidade com um vetor autorregressivo.

Os autores conseguiram determinar, por meio destas metodologias, a relação de causalidade entre ensino médio (tanto técnico quanto comum) e crescimento econômico, sendo o ensino causador do crescimento econômico. Também verificaram que a causalidade corre do crescimento econômico para a educação superior ${ }^{16}$.

Afzal et al. (2012) utilizaram a metodologia de Afzal et al (2011) como base para sua análise. ${ }^{17}$ Como os autores estimaram a relação de causalidade com a metodologia de Toda e Yamamoto (1995), os resultados demonstraram que existe uma relação de bicausalidade entre educação e crescimento econômico para o Paquistão do período entre 1972 e 2009. O diferencial deste estudo é a forma com que os autores constroem a proxy para educação, construindo um índice que abrange taxa de matrícula do ensino primário, secundário e superior, ponderado com a taxa de matrícula total. Contudo, pode ser sujeito a uma possível omissão de dados ao não considerar (pela dificuldade de acompanhamento para construção dos dados) a taxa de abandono escolar.

Aghion et al. (2009) desenvolveram um modelo para estimar o impacto e a causalidade da educação no crescimento econômico, sendo divididos em níveis de educação e variáveis nos quais estes níveis impactariam no mundo real (que agregassem o máximo de informações que são possíveis para gerar uma melhor estimativa de um estudo que envolve educação). Ao invés da média de anos de estudos (que os autores criticam severamente), modelam fatores que normalmente não são comuns nos trabalhos: incorporam o efeito da migração, da proximidade da fronteira tecnológica e da característica sobre a qualidade do capital humano (especializado e não especializado).

Os autores modelaram a relação da proximidade de trabalhadores especializados e não especializados das fronteiras tecnológicas, em que quanto maior a distância do local da fronteira, maior é a tendência em imitar a inovação, sendo assim o incentivo a contratar um trabalhador qualificado menor do que nas

${ }^{16}$ Os resultados deste estudo foram com 1, 4 e 5 defasagens para as metodologias Granger comum, Hsiao e DL-VAR respectivamente.

${ }^{17}$ Estes estudos construíram um indicador da educação como variável representativa, que é dado por:

em que

$$
I_{e}=\frac{2}{3} A L I+\frac{1}{3} G E I
$$

e

$$
A L I=\frac{A L R-\min }{\max -\min }
$$

$$
G E I=\frac{G E R-\min }{\max -\min }
$$

No qual ALI é o Adult Literacy Index (índice de alfabetização adulta), composto pela Adult Literacy Rate (taxa de alfabetização adulta - ALR) e pela Gross Enrollment Index (índice de matrículas totais - GEI) composto pela Gross Enrollment Rate (taxa bruta de matrícula - GER) e os índices máximos e mínimos de cada um. 
proximidades da fronteira tecnológica. $\mathrm{Na}$ fronteira, há o incentivo para criação de inovação tecnológica. ${ }^{18}$ Para os trabalhadores, estas variáveis estão relacionadas aos salários: quanto menor a distância da fronteira tecnológica, maior seria a utilização de trabalhadores qualificados e, por consequência, maior o preço do trabalho destes, induzindo a firma a substituir por trabalhadores não qualificados. A migração tem importância fundamental, uma vez que a oferta dos trabalhadores varia conforme 0 efeito dela. Com isso, Estados em que a oferta de trabalhadores qualificados e que se situam mais próximos da fronteira tecnológica influenciam mais a criação de inovações e, com isso, o crescimento econômico.

De acordo com Aghion et al. (2009), a estimação da relação da educação no crescimento econômico para os Estados Unidos para o período entre 1947 e 2008 se deu pela utilização de variáveis instrumentais e demonstraram que a educação causou o crescimento econômico. O foco dos autores foi verificar os possíveis canais e causas que esta relação se dá.

Para o Brasil, Coelho (2006) replicou a metodologia de Asteriou e Agiomirgianakis para o período entre 1959 a 2000, utilizando como proxy de capital humano o número de matrículas per capita. Procurou saber se existe algum nível de educação que é mais importante para o crescimento econômico que outro, verificando se a proxy é cointegrada e se causa, no sentido de Granger, o crescimento econômico.

Nos vetores de cointegração, utilizou-se vetores autorregressivos defasados em 6 períodos para todos os níveis educacionais. Os resultados indicaram que houve relação de causalidade, de capital humano para o crescimento econômico. Também encontraram indícios de causalidade reversa. Contudo, estes resultados não foram, para todos os níveis de escolaridade, consistentes com a hipótese.

Cardoso (2006) analisou a influência do ensino superior no crescimento econômico brasileiro para o período de 1954 a 1999. A autora testa por meio do Teste de Não-Causalidade de Granger se a taxa de crescimento da educação superior tem uma relação de causa na taxa de crescimento econômico. Verificou a estacionaridade das séries com o Teste de Dickey-Fuller e realizou o teste de cointegração de Johansen, em que busca verificar uma relação de longo prazo entre as séries. Contudo, não encontra interação entre o ensino superior e o crescimento econômico, nem causalidade de Granger. Assim, para o Brasil, o ensino superior não causaria o crescimento econômico e vice-versa.

Dias, Dias e Lima (2009) destacaram um fator importante para análises que envolvem o capital humano: na maior parte dos modelos econométricos supõe-se que há uma relação linear entre crescimento econômico e capital humano. Os autores demonstraram a não-linearidade entre estas duas variáveis para o Brasil, apontando que a hipótese de linearidade é erroneamente e amplamente utilizada. Considerando isto, os autores verificaram a relação de causalidade direta entre educação e crescimento econômico (com educação sendo medido em anos de estudo dos indivíduos) utilizando a metodologia de Arellano e Bond (1991) para o período entre 1985 e 2000 e, além disso, qual seria a quantidade de anos de estudo que ocasionaria o maior crescimento econômico.

Os resultados encontrados nesse estudo foi que a educação é causadora do crescimento econômico com uma defasagem de 5 anos. Deste modo, políticas educacionais de longo prazo seriam fundamentais para um aumento significativo no

\footnotetext{
${ }^{18}$ Esta afirmativa se dá pela medida da contribuição de trabalhadores qualificados nos dois cenários. Quanto maior a proximidade da fronteira tecnológica, maior a contribuição, sendo gerador de inovações. O inverso é verdadeiro.
} 
crescimento do PIB de um país. Além disso, entre 4,5 e 4,7 anos seriam as quantidades de anos de estudo que causaria o pico máximo no crescimento econômico, de acordo com a relação não-linear entre educação e crescimento econômico. Este número pode ser utilizado como uma meta para os Estados com média de escolaridade abaixo da estimada.

Boldin, Morote e McMullen (1996), analisando Argentina, Brasil e Chile, procuraram verificar a conexão entre ensino superior e crescimento econômico no período entre 1960 e 1996. Para isto, utilizaram a taxa de matrícula no ensino superior e a taxa de crescimento do PIB dos países e verificaram que o ensino superior tinha relação positiva de causalidade com o crescimento econômico para o Brasil. Contudo, para o Chile não foram encontrados nem correlações nem causalidade entre as duas variáveis. ${ }^{19}$ Os comportamentos dos dados diferem entre si, podendo influenciar na estimação da causalidade, uma vez que o Teste de Causalidade de Granger possui como base um modelo VAR linear.

De acordo com os autores, este resultado demonstra que as características da educação superior (sua grade curricular) são importantes e provocam o crescimento econômico, pois se a estrutura econômica e social for conectada afim de que o graduado consiga fazer o uso do conhecimento adquirido no ensino superior, isto causaria aumentos no crescimento econômico do país.

Sen, Kaya e Alpasan (2015) procuraram verificar a relação de causalidade entre os gastos com educação e saúde no crescimento econômico em países em desenvolvimento (Argentina, Brasil, Chile, India, Indonésia, México, África do Sul e Turquia) no período entre 1995 e 2012. A relação de países foi considerada por serem territórios nos quais as taxas de crescimento são maiores em relação a outros países em desenvolvimento, tem crescido o potencial para fazerem parte do grupo das maiores economias do mundo e, exceto o Chile, são membros do G-20, representando uma influência maior na economia mundial.

O método utilizado foi o de Konya (2006) apud Sen, Kaya e Alpasan (2015) que considera a dependência seccional dos dados e a heterogeneidade entre os países. Deste modo, aplica-se o teste de causalidade de Granger para cada país a fim de observar as relações contemporâneas entre os países citados. É possível identificar também a relação que cada país causa no outro.

Os resultados demonstram uma relação unidirecional significativa entre gastos em educação e crescimento econômico, ao nível de significância de 10\%, para apenas a Argentina e Indonésia. Para o Brasil, apenas foi detectada a relação da educação em conjunto com gastos em saúde, estes dois causando o crescimento econômico no sentido de Granger. Uma possível justificativa, segundo os autores, é que dado os limitados recursos que o governo possui para gasto, a fração direcionada a saúde e educação nos países que não obtiveram significância é muito baixa. Outra justificativa seria que a burocracia e a corrupção para direcionamento dos recursos em educação e saúde nos países (em todos) seja alta, uma vez que as causalidades foram determinadas apenas a ponto de $10 \%$ de significância estatística.

Direção da causalidade: Crescimento econômico - educação

\footnotetext{
${ }^{19}$ Vale dizer que as variáveis, nos três países analisados, se comportam de maneira diferente. Tanto a taxa de crescimento dos alunos matriculados quanto o PIB per capita no Brasil tem tendência decrescente no período analisado. Para a Argentina, a taxa de matrícula decresce e o PIB per capita possui formato em U. Para o Chile, ambos tendem a demonstrar um formato em U.
} 
Por outro lado, Bils e Klenow (2000) encontraram que o crescimento econômico causa um aumento na escolaridade quando analisaram uma amostra de países para o período entre 1990 e 1996. De acordo com os autores, em um modelo para estimar a correlação escolaridade-crescimento, este canal era fracamente estimado devido aos retornos marginais de educação. Quanto menores os retornos marginais, menores ou não significativos eram as estimativas para a determinação do canal educação-crescimento econômico. Na discussão crescimento-escolaridade, por meio do método por calibração do modelo especificado pelos autores, resultaram em uma evidência favorável para o canal de causalidade crescimento-escolaridade.

Danacia, Belascu e llie (2010) demonstraram que, com dados de 1980 a 2008, o crescimento econômico causava aumentos na educação superior na Romênia. Os autores utilizaram os testes de Dickey-Fuller, Dickey-Fuller Aumentado, Phillips-Peron e Kwiatkowski para verificar a integração e estacionariedade das séries de tempo utilizadas. Também, utilizaram o teste de Johansen (1995) para verificar a cointegração das séries antes de estimar a metodologia de Granger. Uma particularidade deste estudo é que os autores enfatizam a revolução de 1989, naquele país, como um evento que marcou o aumento da quantidade e qualidade das universidades públicas e a criação de inúmeras universidades particulares. A ocorrência deste evento, de certa forma, pode ter influenciado o resultado da série pós-1989. Para evitar isso, eles utilizaram o crescimento econômico per capita, uma vez que a população do país cresceu após o evento.

Chaudhary, Iqbal e Gillani (2009) observaram que o crescimento econômico causou a educação a nível superior no Paquistão entre 1972 e 2005. Os autores procuraram verificar, utilizando o método de causalidade de Toda e Yamamoto (1995), a direção da causalidade no crescimento econômico de variáveis como trabalho, capital e educação (especificamente educação superior). A escolha das variáveis foi baseada em uma das sensibilidades da técnica de Granger (1969): a estimação bi variável que pode induzir ao viés de especificação dos modelos, uma vez que há mais fatores que ajudam a educação a aumentar o crescimento econômico. Isto justifica a abordagem de Toda e Yamamoto (1995) utilizada pelos autores, composta pela estimação de um VAR aumentado no qual garante a distribuição assintótica chiquadrado, uma vez que satisfaz as condições de integração e cointegração do processo de estimação.

Francis e lyare (2006), utilizando modelos de cointegração e correção de erro ${ }^{20}$, analisaram a causalidade entre educação e desenvolvimento em países caribenhos (Jamaica, Trinidad e Tobago e Barbados). Gastos com educação per capita e Receita Bruta Nacional foram utilizadas como proxies para educação e desenvolvimento econômico, respectivamente. Os autores utilizaram dados de 1964 até 1998 para a análise e verificaram uma relação unidirecional entre crescimento econômico e educação para todos os países no curto e longo prazo. Para a Jamaica, no entanto, foi encontrada uma relação de causalidade de curto prazo entre educação e crescimento econômico.

Os autores pontuam que uma possível explicação para este efeito seria que o sistema educacional caribenho não foi desenvolvido e direcionado para a implementação e melhoramento de pessoas para assuntos técnicos e científicos,

20 De acordo com Granger (1986), modelos de correção de erro produzem melhores estimativas de causalidade de curto prazo e provém a dinâmica necessária para obter o equilíbrio de longo prazo quando as variáveis são cointegradas. 
ramos essenciais para o desenvolvimento da indústria nos países. Outra razão seria que, pela taxa de desemprego dos países se mostrar alta, ela impede que os trabalhadores direcionem um tempo para especialização, promovida pelo avanço tecnológico.

Na mesma linha que Francis e lyare (2006), Uche, Ihugba e Nwosu (2013) analisaram a causalidade entre educação e crescimento econômico para a Nigéria no período entre 1981 e 2011. Utilizando o teste de causalidade de Granger em um Modelo de Vetor de Correção de Erros, os autores encontraram que o log do PIB causa os gastos em educação. Um fator ressaltado no trabalho é que a falta de transparência dos dados governamentais obtidos pode alterar as conclusões, uma vez que o país possui alto índice de corrupção, além de que dos outros testes efetuados ( 6 testes no total), apenas um foi estatisticamente aceito, podendo ser explicado pelas características dos dados do país.

As observações de Benhabib e Spiegel (1994) contribuem para a discussão de causalidade educação-crescimento. Segundo os autores, o salário apenas cresce pelo fato de haver um processo de sinalização da capacidade cognitiva do trabalhador, significando que não existe uma relação de causalidade na direção educação-crescimento. Ou seja, a relação esperada de causalidade educaçãocrescimento econômico não é imutável em um horizonte temporal, pois quando a demanda por trabalhadores qualificados está estagnada em um país, a elevação da oferta apenas reduz os retornos à escolaridade.

Para a relação de causalidade do sentido crescimento econômico-educação, não foram encontrados trabalhos para o Brasil. Trabalhos internacionais que continham o país na amostra não resultaram em parâmetros significativos para esta direção de causalidade.

Com isso, é possível sintetizar os procedimentos metodológicos realizados e seus resultados nos trabalhos internacionais e brasileiros. O Quadro 1 mostra os trabalhos internacionais e nacionais sobre o debate da causalidade entre educação e crescimento econômico (CE).

Dos cinco trabalhos analisados para o Brasil, três obtiveram resultados estatisticamente significativos, conforme Quadro 1. Boldin, Morote e McMullen (2000) e Coelho (2008) utilizaram a metodologia de Granger (1969) como forma de identificação da direção de causalidade entre educação e crescimento econômico, com todos partindo do primeiro para o segundo. Cardoso (2006), com a mesma metodologia, não encontrou resultados significativos. Sen, Kaya e Alpasan (2015), utilizando a metodologia de Konya (2006), não encontraram resultados significativos para a relação de causalidade aplicados ao Brasil.

O trabalho de Boldin, Morote e McMullen (2000) encontrou uma relação de causalidade entre educação superior e crescimento econômico, correndo do primeiro para segundo. Sabendo que no período analisado para o Brasil (entre 1960 e 1996) a taxa de matrícula no ensino superior e a taxa de crescimento decresceram ao longo do tempo, segundo os autores essas taxas podem ser explicadas pelo desenho do sistema educacional do país, uma vez que dificulta a entrada de estudantes de baixa renda a ingressar em instituições públicas de ensino superior, o que converge com as observações de Birdsall et al (1996). ${ }^{21}$

Ressalta-se o resultado positivo sobre a causalidade do nível superior pois, de acordo com os autores, não há consenso sobre a influência do ensino superior em

\footnotetext{
${ }^{21}$ Birdsall et al (1996) aponta que a falta de um sistema educacional bem desenhado a nível superior minimizou o crescimento e a estabilidade política dos anos 80 e dos anos 90 no Brasil.
}

58 Economia \& Região, Londrina (Pr), v.8, n.2, p.41-67, jul./dez. 2020 
Rodrigo Calmon Ribeiro, Solange C. Inforzato Souza

questão de causalidade, no crescimento econômico. A maior parte dos trabalhos encontra uma relação inversa ao apresentado nesse trabalho.

QUADRO 1 - Síntese dos trabalhos sobre a causalidade entre educação e crescimento econômico em outros países

\begin{tabular}{|c|c|c|c|c|c|}
\hline Autores & Período & Países & Nível educação & Resultado & Metodologia \\
\hline $\begin{array}{l}\text { Meulemeester e } \\
\text { Rochat (1995) }\end{array}$ & 1887-1987 & $\begin{array}{lr}\text { Suécia, } & \text { Reino } \\
\text { Unido, Japão e } \\
\text { França }\end{array}$ & Ensino Superior & $\begin{array}{l}\text { Educação Superior } \\
\Rightarrow \text { CE }\end{array}$ & $\begin{array}{l}\text { Granger } \\
(1969)\end{array}$ \\
\hline $\begin{array}{l}\text { Bils e } \text { Klenow } \\
(2000)\end{array}$ & 1960-1990 & 52 países & $\begin{array}{l}\text { Todos os níveis } \\
\text { educacionais }\end{array}$ & $\mathrm{CE} \Rightarrow$ Educação & Calibração \\
\hline $\begin{array}{l}\text { Boldin, Morote e } \\
\text { McMullen (2000) }\end{array}$ & 1960-1996 & $\begin{array}{l}\text { Argentina, Brasil e } \\
\text { Chile }\end{array}$ & $\begin{array}{l}\text { Educação } \\
\text { Superior }\end{array}$ & Educação $\Rightarrow$ CE & $\begin{array}{l}\text { Granger } \\
(1969)\end{array}$ \\
\hline $\begin{array}{l}\text { Asteriou e } \\
\text { Agiomirgianakis } \\
(2001)\end{array}$ & 1960-1994 & Grécia & $\begin{array}{l}\text { Todos os níveis } \\
\text { educacionais }\end{array}$ & $\begin{array}{l}\text { Primário e } \\
\text { Secundário } \Rightarrow \text { CE } \\
\text { Educação Superior não } \\
\text { encontrada }\end{array}$ & $\begin{array}{l}\text { Granger } \\
\text { (1969) }\end{array}$ \\
\hline Kui (2006) & 1978-1996 & China & $\begin{array}{l}\text { Todos os níveis } \\
\text { educacionais }\end{array}$ & $\begin{array}{l}\text { Educação } \\
\text { Básica } \Rightarrow \text { CE } \\
\text { Educação } \\
\text { Superior } \Rightarrow \text { CE }\end{array}$ & $\begin{array}{l}\text { Granger } \\
\text { (1969) }\end{array}$ \\
\hline $\begin{array}{l}\text { Francis e lyare } \\
(2006)\end{array}$ & 1964-1998 & $\begin{array}{l}\text { Jamaica, } \\
\text { Trinidade } \\
\text { Tobago } \\
\text { Barbados }\end{array}$ & $\begin{array}{l}\text { Todos os níveis } \\
\text { educacionais }\end{array}$ & $\mathrm{CE} \Rightarrow$ Educação & VECM \\
\hline Cardoso (2006) & 1954-1999 & Brasil & $\begin{array}{l}\text { Educação } \\
\text { Superior }\end{array}$ & $\begin{array}{ll}\text { Não } & \text { encontrou } \\
\text { causalidade }\end{array}$ & $\begin{array}{l}\text { Granger } \\
(1969)\end{array}$ \\
\hline Coelho (2008) & $1959-2000$ & Brasil & $\begin{array}{l}\text { Educação } \\
\text { Superior }\end{array}$ & Educação $\Rightarrow$ CE & $\begin{array}{l}\text { Granger } \\
(1969)\end{array}$ \\
\hline $\begin{array}{l}\text { Aghion et al } \\
(2009)\end{array}$ & 1947-2008 & Estados Unidos & $\begin{array}{l}\text { Todos os níveis } \\
\text { educacionais }\end{array}$ & Educação $\Rightarrow$ CE & $\begin{array}{l}\text { Variaveis } \\
\text { Instrumentais }\end{array}$ \\
\hline $\begin{array}{l}\text { Chaudhary, } \\
\text { lqbal e Gillani } \\
(2009)\end{array}$ & $1972-2005$ & Paquistão & $\begin{array}{l}\text { Todos os níveis } \\
\text { educacionais }\end{array}$ & $\begin{array}{l}\text { Nível Primário } \Rightarrow \mathrm{CE} \\
\text { Educação } \\
\text { Superior } \Rightarrow \mathrm{CE}\end{array}$ & $\begin{array}{l}\text { Toda e } \\
\text { Yamamoto } \\
(1995) \\
\end{array}$ \\
\hline $\begin{array}{lcc}\text { Dias, Dias } & \text { e } \\
\text { Lima (2009) }\end{array}$ & $1985-2000$ & Brasil & $\begin{array}{l}\text { Todos os níveis } \\
\text { educacionais }\end{array}$ & Educação $\Rightarrow$ CE & $\begin{array}{l}\text { Arellano e } \\
\text { Bond (1991) }\end{array}$ \\
\hline $\begin{array}{l}\text { Danacia, } \\
\text { Belascu e Ilie } \\
(2010)\end{array}$ & 1980-2008 & Romênia & Ensino Superior & CE Ecałação Superior & $\begin{array}{l}\text { Granger } \\
\text { (1969) }\end{array}$ \\
\hline Afzal et al (2012) & 1972-2009 & Paquistão & $\begin{array}{l}\text { Todos os níveis } \\
\text { educacionais }\end{array}$ & Educação $\Rightarrow$ CE & $\begin{array}{l}\text { Toda } \\
\text { Yamamoto } \\
(1995)\end{array}$ \\
\hline $\begin{array}{l}\text { Uche, lhugba e } \\
\text { Nwosu (2013) }\end{array}$ & $1981-2011$ & Nigéria & $\begin{array}{l}\text { Todos os níveis } \\
\text { educacionais }\end{array}$ & CE $\Rightarrow$ Educação & $\begin{array}{l}\text { Granger } \\
(1969) \\
\text { VECM }\end{array}$ \\
\hline $\begin{array}{ll}\text { Yurtkuran } & \text { e } \\
\text { Terzi (2015) } & \end{array}$ & 1950-2012 & Turquia & $\begin{array}{l}\text { Nível Secundário } \\
\text { e Ensino Superior }\end{array}$ & $\begin{array}{l}\text { Nível } \\
\text { Secundário } \Rightarrow \text { CE } \\
\text { CE } \Rightarrow \text { Educação } \\
\text { Superior }\end{array}$ & $\begin{array}{l}\text { Dolado- } \\
\text { Lutkepohl } \\
\text { (1996), Hsiao } \\
\text { (1981) e } \\
\text { Granger } \\
(1969)\end{array}$ \\
\hline $\begin{array}{l}\text { Sen, Kaya e } \\
\text { Alpasan (2015) }\end{array}$ & $1950-2010$ & $\begin{array}{l}\text { Argentina, Brasil, } \\
\text { Chile, India, } \\
\text { México, África do } \\
\text { Sul e Turquia }\end{array}$ & $\begin{array}{l}\text { Todos os níveis } \\
\text { educacionais }\end{array}$ & $\begin{array}{l}\text { Não encontraram } \\
\text { causalidade }\end{array}$ & Konya (2006) \\
\hline
\end{tabular}

Fonte: Elaborado pelos autores.

Como a metodologia utilizada foi o Teste de Não Causalidade de Granger, com base na definição em que precedência temporal seja corretamente mais aplicável, o trabalho dos autores é de grande relevância para o Brasil pois um maior acesso à 
educação superior, principalmente em áreas como as de engenharias, acarretou em um aumento no crescimento econômico brasileiro no longo prazo.

Já Dias, Dias e Lima (2009) utilizaram a metodologia de Arellano e Bond (1991), encontrando o mesmo resultado. Esta metodologia é estimada por variáveis instrumentais e considera os efeitos do crescimento econômico passado sobre o crescimento atual, em nível e em diferença. A ideia é que se o crescimento econômico defasado contém toda a informação sobre as variáveis que o compõe, o modelo é capaz de estimar os efeitos do período anterior e o que exceder deveria estar associado ao capital humano. A contribuição dos autores foi estimar um modelo com a hipótese de que a escolaridade e o crescimento econômico não possuam uma relação linear.

Similar ao trabalho de Boldin, Morote e McMullen (2000), Coelho (2008), com probabilidade de 1\%, o primeiro nível do ensino superior analisado (graduação) e o ensino fundamental provocam, no sentido de Granger, o crescimento do PIB brasileiro. Para o nível de 5\%, também resultou no ensino superior como causador do crescimento econômico, resultando em uma causalidade reversa. Como esperado, a partir da análise da literatura internacional, o ensino fundamental resultou na causalidade do crescimento econômico no Brasil. A similaridade ao trabalho de Boldin está na causalidade do ensino superior no crescimento econômico.

Segundo os autores, a hipótese 2 do trabalho (de que o capital humano causa o crescimento econômico) não é tão consistente, uma vez que de 10 séries estimadas, 6 apresentam relação direta de causalidade entre capital humano e crescimento econômico (entre ensino fundamental, médio, graduação e pós-graduação), enquanto que 4 destas não deram significância estatística e/ou obtiveram resultados de causalidade reversa com uma probabilidade de $15 \%$.

Desta maneira, não permite apontar uma relação de direção causal preferencial para todas as probabilidades analisadas. Ainda, pelo fato de ser uma replicação do trabalho de Asteriou e Agiomirgianakis (2001), pode refletir momentos econômicos e educacionais diferentes nos países: a oferta e a demanda por ensino superior podem refletir um padrão diferente do que é na Grécia, sendo oferecido pelo governo mas apresentando uma taxa decrescente de matriculados, uma vez que na Grécia é sob taxas crescentes. Também, para o trabalho grego, foi identificada uma relação positiva de causalidade a nível médio de educação, o que no Brasil esta hipótese foi rejeitada. Como os trabalhos de Cardoso (2006) e de Sen, Kaya e Alpasan (2015) não obtiveram relação significativa de causalidade, não foram mencionados nesta seção.

Em síntese, na verificação dos trabalhos que conseguiram estabelecer relações de causalidade entre educação e crescimento econômico para o Brasil, os trabalhos de Dias, Dias e Lima (2005), Coelho (2008) e Boldin, Morote e McMullen (2000) são extremamente importantes para a literatura nacional e contribuem para o debate sobre a causalidade entre as variáveis no quesito de apresentarem relações que correm do capital humano para o crescimento econômico, confirmando esta relação no ensino fundamental e divergindo da maior parte dos trabalhos internacionais quanto ao nível superior.

No quesito metodológico, grande parte dos trabalhos nacionais utilizaram o método tradicional de Granger (1969), e os outros os de Konya (2006), Arellano e Bond (1991) e Toda e Yamamoto (1995). Muito utilizado na literatura sobre causalidade, o método de Granger (1969) pode ser alvo de questionamentos sobre sua eficácia em verificar a causalidade de um fenômeno, como os demonstrados em 
Henry (2017). Ainda assim desperta o interesse dos autores em determinar a relação de causalidade entre educação e crescimento econômico, resultando em observações úteis para a literatura brasileira acerca do tema. Contudo, não apresentam inovação quanto ao desenvolvimento de métodos novos de estimação da causalidade, sendo aplicados instrumentos já utilizados por outros autores internacionais.

Os trabalhos internacionais utilizam metodologias diferentes da proposta por Granger (1969), com o objetivo de incorporar e sanar as barreiras metodológicas que o conceito de causalidade possui, sendo citados outros seis métodos para este fim. $O$ detalhamento desses métodos não é de escopo deste trabalho, mas auxiliam a identificar as possíveis opções para autores que buscam melhores maneiras para verificar a relação de causalidade entre educação e crescimento econômico.

\section{CONCLUSÃO}

O objetivo deste artigo foi mostrar o debate sobre a causalidade entre educação e crescimento econômico na literatura econômica internacional e verificar a contribuição brasileira ao debate. Mais da metade dos trabalhos analisados para outros países demonstraram uma relação de causalidade entre educação e crescimento econômico (nove trabalhos), partindo da primeira para a segunda. Quando desagregados em níveis educacionais, três artigos evidenciaram que a educação (ensino básico até o ensino médio/high school) causa o crescimento econômico. Dos estudos que encontraram que o crescimento econômico possui uma associação positiva com a educação (5 trabalhos), três demonstraram que o crescimento econômico de um país possui relação de causalidade com o ensino superior.

Algumas observações devem ser feitas: o padrão da literatura sobre a causalidade entre educação e crescimento é destacado diversas vezes como sendo o de que (i) a educação básica causa o crescimento econômico, e (ii) há uma área cinza sobre o crescimento econômico como causa da expansão do ensino em nível superior e o ensino médio/high school. Há trabalhos com estimações nãosignificativas e outros com uma relação positiva direcional do ensino médio para o crescimento econômico.

Para o Brasil, contudo, todos os níveis educacionais analisados são mostrados como sendo motivadores do crescimento econômico, o que demonstra que mesmo alterando os métodos de estimação e as bases de dados analisadas, a educação, em todos os níveis, é fator básico para melhorar o desempenho econômico da nação.

Não houve estimações significativas quanto ao efeito causa do crescimento econômico sobre o nível de ensino superior no Brasil, denotando um padrão diferente dos trabalhos internacionais. Pode haver duas razões para explicar este resultado: primeiro, a de que os meios para beneficiar o setor educacional estejam sendo subutilizados (como gastos em educação e políticas educacionais); ou, segundo, que o momento econômico dos períodos analisados não tenham influência quanto à relação entre crescimento econômico e educação, demonstrando que o nível educacional brasileiro não tenha tanta participação no crescimento a ponto de não sofrer a sua influência, podendo ser possível expandir sua área de contribuição no crescimento econômico.

É possível concluir que o Brasil possui estudos que confirmam a importância da educação como determinante do crescimento econômico, devendo ser objeto de análise para as políticas educacionais visando um retorno econômico e social ao país. 
Sugere-se para trabalhos futuros que seja feita uma atualização dos estudos sobre a direção da causalidade entre educação e crescimento econômico e que utilize métodos recentes de determinação da causalidade, visando a robustez das estimações e incorporação de variáveis importantes para analisar a relação discutida, não inseridas nos modelos dos autores aqui citados.

A dificuldade em estudar a relação de causalidade entre duas variáveis serve de motivação para estudos com foco na definição do ambiente em que a causalidade está inserida. O contexto institucional e social interfere diretamente nas características trazidas nas bases de dados, sendo participante atuante na discussão de causalidade de fenômenos.

\section{REFERÊNCIAS}

AFZAL, M.; MALIK, M. E.; BEGUM, I.; SARWAR, K.; FATIMA, H. Relationship among Education, Poverty and Economic Growth in Pakistan: An Econometric Analysis. Journal of Elementary Education, v. 22, n. 1, p. 23-45, 2012.

AFZAL, M.; REHMAN, H. FAROOQ, M. Q.; SARWAR, K. Education and Economic Growth in Pakistan: A Cointegration and Causality Analysis. International Journal of Educational Research, v. 50, p. 321-335, 2011.

AGHION, P.; BOUSTAN, L.; HOXBY, C.; VANDENBUSSCHE, J. The Causal Impact of Education on Economic Growth: Evidence from U.S. Unpublished paper, 2009.

ARELLANO, M.; BOND, S. Some Tests of Specification for Panel Data: Monte Carlo Evidence and an Application to Employment Equations. The Review of Economic Studies, v. 58, n. 2, p. 277-297, 1991.

ASTERIOU, D.; AGIOMIRGIANAKIS, G. M. Human Capital and Economic Growth: Time Series Evidence from Greece. Journal of Policy Modeling, v.23, n. 5, p. 481489, 2001.

AZARIADIS, C.; DRAZEN, A. Threshold Externalities in Economic Development. The Quarterly Journal of Economics, v. 105, p. 501-526, 1990.

BARRO, R. J. Economic Growth in a Cross-Section of Countries. Quarterly Journal of Economics, v. 106, p. 407-443, 1991.

BARRO, R. J.; MARTIN, X. S. i. Technological Diffusion, Convergence, and Growth. Cambridge, Massachusetts: NBER, 1995. Texto para discussão, n. 5151.

BARBOSA FILHO, F. d. H.; PESSÔA, S. S. Retorno da Educação no Brasil. Pesquisa e Planejamento Econômico, v. 38, n. 1, 2008.

BECKER, G. S. Investment in Human Capital: A Theoretical Analysis. The Journal of Political Economy, v.70, n. 5, p. 9-49, 1962.

BENHABIB, J.; SPIEGEL, M. M. The Role of Human Capital in Economic Development Evidence from Aggregate Cross-country Data. Journal of Monetary Economics, v. 34, n. 2, p. 143-173, 1994. 
BILS, M.; KLENOW, P. J. Does Schooling cause Growth? American Economic Review, Vol. 90, N. 5, p. 1160-1183, 2000.

BIRDSALL, N.; SABOT, R. Opportunity Foregone: Education in Brazil. John Hopkins University Press. 1996.

BISHOP, J. The Impact of Academic Competencies of Wages, Unemployment, and Job Performance. Carnegie-Rochester Conference Series on Public Policy, 37, p. 127-194, 1992.

BOLDIN, R.; MOROTE, E.; MCMULLEN, M. Higher Education and Economic Growth in the Latin American Emerging Markets.1996.

BRUNELLO, G.; CHECCHI, D. School Quality and Family Background in Italy. Economics of Education Review, v. 24, p. 563-577, 2005.

CARDOSO, F.d.R. Educação Superior e Crescimento Econômico.2006. Dissertação de Mestrado em Economia - Universidade Federal do Rio Grande do Sul, Porto Alegre, 2006.

CASTRO, C. d. M. Investment in Education in Brazil: a Study in Two Industrial Communities. 1970. Tese de Doutorado, Graduate School of Vanderbilt University, Nashville, 1970.

CHAUDHARY, A. R.; IQBAL, A.; GILLANI, S. Y. M. The Nexus between Higher Education and Economic Growth: An Empirical Investigation for Pakistan. Pakistan Journal of Commerce and Social Sciences, v. 3, n. 1, p. 1-9, 2009.

COELHO, R. de A. Níveis de Educação, Capital Humano e Crescimento Econômico no Brasil: Um Estudo sobre as Relações de Causalidade. 2006. Dissertação de Mestrado em Economia - Universidade Federal de Santa Catarina, Florianópolis, 2006.

DANACIA, D-E.; BELASCU, L.; ILIE, L. The Interactive Causality between Higher Education and Economic Growth in Romania. International Review of Business Research Papers. v. 6, n. 4, pp. 491-500, 2010.

DAVIDSON, R.; MACKINNON, J. G. Estimation and Inference in Econometrics. New York, Oxford University Press, 1993.

DIAS, J.; DIAS, M. H. A.; LIMA, F. F. Os Efeitos da Política Educacional no Crescimento Econômico: Teorias e Estimativas Dinâmicas em Painel de Dados. Revista de Economia Política, v. 29, p. 232-251, 2009.

DOLADO, J.; LUTKEPOHL, H. Making Wald Tests Work for Co-Integrated VAR Systems. Econometric Review, v. 15, p. 369-386, 1996.

EDGEWORTH. F. Y. Methods of Statistics. Journal of the Statistical Society of London, p. 181-217, 1885.

EICHLER, M. Causal Inference in Time Series Analysis. Causality: Statistical Perspectives and Applications, p. 327-354, 2012. 
ENGEL, E. Der Werth des Menschen. Belin: Verlag von Leonhard Simion, 1883.

FARR, W. The Income and Property Tax. Journal of the Statistical Society of London, v. 16, n. 1, p. 1-44, 1853.

FRANCIS, B.; IYARE, S. Education and Development in the Caribbean: a Cointegration and Causality Approach. Economics Bulletin, v. 15, n. 2, p. 1-13, 2006.

GHEZ, G.; BECKER, G. S. The Allocation of Time and Goods over the Life Cycle. NBER Books, National Bureau of Economic Research, Inc, 1975.

GRANGER, C. W. Investigating Causal Relations by Econometric Models and CrossSpectral Methods. Econometrica: Journal of the Econometric Society, p. 424-438, 1969.

GRANGER, C. W. Developments in the Study of Cointegrated Economic Variables. Oxford Bulleting of Economics and Statistics, v. 48, n. 3, p. 213-228, 1986.

HANUSHEK, E.A.; KIMKO, D.D.; Schooling, Labor-Force Quality, and the Growth of Nations. The American Economic Review, v. 90, n. 5, p. 1184-1208, 2000.

HECKMAN, J. J.; LI, X. Selection Bias, Comparative Advantage and Heterogeneous Returns to Education: Evidence from China in 2000. Pacific Economic Review, v. 9, n. 3, p. 155-171, 2004.

HENDRY, D. F. Granger Causality. European Journal of Pure and Applied Mathematics, v. 10, n. 1, p.12-29, 2017. Disponível em: https://ejpam.com/index.php/ejpam/article/view/2948. Acesso em 2 de fevereiro de 2019.

HOOVER, K. D. Causality in Economics and Econometrics. New Palgrave Dictionary of Economics. 2006.

HSIAO, C. Autoregressive Modelling and Money-Income Causality Detection. Journal of Monetary Economics, v. 7, p. 85-106, 1981.

HUME, D. Essays, Moral, Political and Literary. Liberty Fund Publisher, 1742.

JOHANSEN, S. Identifying Restrictions of Linear Equations with Applications to Simultaneous Equations and Cointegration. Journal of Econometrics, v. 69, p. 111132, 1995.

JÚNIOR, L. H. d. S.; SAMPAIO, Y. Qualidade da Escola e Background Familiar na Formação de Capital Humano no Brasil. Planejamento e Políticas Públicas, n. 45, p.275-300, 2015.

KASSOUF, A. L. The Wage Rate Estimation using the Heckman Procedure. Brazilian Review of Econometrics, v. 14, n. 1, p. 89-107, 1994.

KIKER, B. F. The Historical Roots of the Concept of Human Capital. The Journal of Political Economy, p. 481-499, 1966. 
KONYA, L. Exports and Growth: Granger Causality Analysis on OECD Countries with a Panel Data Approach. Economic Modelling, v. 23, p. 978-992, 2006.

KUI, L. The Interactive Causality between Education and Economic Growth in China. Peking University. Disponível em https://papers.ssrn.com/sol3/papers.cfm?abstract id=920624 Acesso em: 20 de janeiro 2019 .

LANGONI, C. G. Distribuição da Renda e Desenvolvimento Econômico do Brasil: Uma Reafirmação. Escola de Pós-Graduação em Economia - Fundação Getúlio Vargas, Rio de Janeiro, 1974.

LINDAHL, M.; KRUEGER, A. B. Education for Growth: Why and for Whom? Journal of Economic Literature, American Economic Association, v. 39, n. 4, p. 1101-1136, 2001.

LIST, F.; HENDERSON, W. O. The Natural System of Political Economy, 1837. Frank Cass \& Company, 1983.

LUCAS, R. E. On the Mechanics of Economic Development. Journal of Monetary Economics, v. 22, n. 3-42, 1988.

MEULEMEESTER, J-L. D.; ROCHAT, D. A Causality Analysis of the Link between Higher Education and Economic Development. Economics of Education Review, v. 14, n. 4, p. 351-361, 1995.

MILL, J.S. A System of Logic. Book IV, Create Space Independent Publishing Platform, 1851.

MINCER, J. Investment in Human Capital and Personal Income Distribution. Journal of Political Economy, v. 66, n. 4, p. 281-302, 1958.

MINCER, J. Schooling, Experience and Earnings. Cambridge, Massachusetts. National Bureau of Economic Research. 151p. 1974.

MINCER, J Human Capital and Economic Growth. Cambridge, Massachusetts. National Bureau of Economic Research, 125p. 1981.

MOURA, R. L. d. Testando as Hipóteses de Mincer para o Brasil. Revista Brasileira de Economia, v. 62, n. 4, p. 407-449, 2008.

NAKABASHI, L.; FIGUEIREDO, L. Capital Humano e Crescimento: Impactos Diretos e Indiretos. Belo Horizonte, Minas Gerais: CEDEPLAR,2005. 12p. (Texto para discussão, n. 267).

NAKABASHI, L.; FIGUEIREDO, L. Economic Growth, Convergence and Quality of Human Capital Formation System. Belo Horizonte, Minas Gerais. CEDEPLAR,2005. 12p. (Texto para discussão, n. 265).

NELSON, R. R.; PHELPS, E. S. Investment in Humans, Technological Diffusion, and Economic Growth. The American Economic Review, v.56, n. 12, p. 69-75, 1966. 
PSACHAROPOULOS, G.; PATRINOS, H. A. Returns to Investment in Education: a Further Update. Education Economics, v. 12, n. 2, p. 111-134, 2004.

RESENDE, M.; WYLLIE, R. Retornos para Educação no Brasil: Evidências Empíricas Adicionais. Economia Aplicada, v. 10, n. 3, p. 349-365, 2006.

ROMER, P. M. Endogenous Technological Change. Journal of Political Economy, v. 98, n. 5. 1990.

ROMER, P. M. Two Strategies for Economic Development: Using Ideas and Producing Ideas. The World Bank Economic Review, World Bank, n. 6. N. 1, p. 63-91, 1992.

RODRIGUES, A. A. F. Impacto da Educação no Rendimento Salarial no Brasil de 2001 a 2008. 2010. 101f. Dissertação (Mestrado em Economia) - Universidade Federal do Rio Grande do Sul, Faculdade de Ciências Econômicas, Porto Alegre, 2010.

SACHSIDA, A.; LOUREIRO, P. 1. A.; MENDONÇA, M. J. C. d. Um Estudo sobre Retorno em Escolaridade no Brasil. Revista Brasileira de Economia, v. 58, n. 2, p. 249-265, 2004.

SCHULTZ, T. W. Investment in Human Capital. The American Economic Review, v. 51, n. 1, p. $1-17,1961$.

SCHULTZ, T. W. The Increasing Economic Value of Human Time. American Journal of Agricultural Economics, v. 54, n. 5, p. 843-850, 1972.

SCHULTZ, T. W. The Value of Children: An Economic Perspective.Journal of Political Economy, v. 81, n. 2, p. 2-13, 1973.

SEN, H.; KAYA, A.; ALPASLAN, B. Education, Health and Economic Growth Nexus: A Bootstrap Panel Granger Causality Analysis for Developing Countries. Economics Discussion Paper Series, The University of Manchester, EDP-1502, 2015.

SENNA, J. J. Escolaridade, Experiência no Trabalho e Salários no Brasil. Revista Brasileira de Economia, v. 30, n. 2, p. 163-194, 1976.

SIMON, H. Causal Ordering and Identifiability. Hood, WC \& Koopmans Studies in Econometrics, p. 49-74, 1953.

SMITH, A. A Riqueza das Nações (1776). São Paulo: Abril Cultural, v. 1.p. 101, 1983.

TEMPLE, J. The New Growth Evidence. Journal of Economic Literature, v. 37, n. 1, p. 112-156, 1999.

TODA, H. Y.; YAMAMOTO, T. Statistical Inference in Vector Autorregressions with Possibly Integrated Processes. Journal of Econometrics, v. 66, n. 1, p. 225-250, 1995.

TROSTEL, P.; WALKER, I.; WOOLLEY, P. Estimates of the Economic Return to Schooling for 28 countries. Labor economics, Elsevier, v. 9, n. 1, p. 1-16, 2002. 
UCHE, E.; IHUGBA, O. A.; NWOSU, C. Causal Relationship between Government Budget Allocation to the Economic Sector and Economic Growth. Discourse Journal of Education Research, v. 1, n. 8, p. 54-64, 2013.

UZAWA, H. Optimum Technical Change in an Aggressive Model of Economic Growth. International Economic Review, v. 6, n. 1, p. 18-31, 1965.

VENNIKER, R. Social Returns to Education: A Survey of Recent Literature on Human Capital externalities. CPB Netherlands Bureau for Economic Policy Analysis, Report 00/1. The Hague, 2000.

WÖBMANN, L. Specifying Human Capital: A Review, Some Extensions, and Development Effects. Kiel, Germany. Kiel Institute of Economics, 2000. (Texto para discussão, n. 1007).

YOUNG, A.; LEVY, D.; HIGGINS, M. J. Many Types of Human Capital and Many Roles in U.S. Growth: Evidence from Country-Level Educational Attainment Data. Cambridge, Massachusetts. Harvard University, 2004. (Texto para discussão, n. 402).

YURTKURAN, S.; TERZI, H. Does Education Affect Economic Growth in Turkey? A Causality Analysis. Iktisadi ve Idari Bilimler Fakultesi Dergisi, v. 30, n. 2, p. 19-38, 2015.

ZELLNER, A. Causality and Econometrics. Carnegie-Rochester Conference Series on Public Policy, v. 10, p. 9-54, 1979. 